\title{
A COMMENTARY
}

\section{Paul T. Menzel $\dagger$}

Expectations play a significant and widespread role in the morality of ordinary life. Leslie Francis has drawn a helpful and largely accurate picture of the conditions of their moral relevance: their reasonableness, encouragement, longevity, centrality in a person's life, and consistency with background justice. ${ }^{1}$ In health care in particular it is important to keep these limits on the moral force of expectations clearly in mind, for it is virtually inevitable that a rational and decent system of care will disappoint patients' and subscribers' expectations at critical and disputed points. The main reason is simply the oft-rehearsed point about the effect of insurance: a sharp escalation of people's desire to use services regardless of increasing cost relative to statistical marginal benefit. Add to this either employer or societal provision of insurance and people naturally come to expect coverage of a wide range of care whose cost is little object. Any medical economy with a high incidence of insurance will need to find some way to bring expectations under control.

The combination of these expectations with the need to control them constitutes an extremely explosive mixture for any legal system that tries to see its justification as largely moral. Take the combination of two of Francis's moral factors, the reasonability of expectations and their encouragement. ${ }^{2}$ It may have not been reasonable, in the most comprehensive sense, for plaintiffs to have had the expectations that they did (coverage of some debatably costworthy service, let us say). Yet those expectations will often have been encouraged, if not by the actual behavior of a defendant employer or insurer, then at least by the larger context of an insured and assisted medical economy. In tort law we should want to keep the heat on the defendant whenever it is she, not just the larger societal situation, who has encouraged the unreasonable expectations; legal

† Professor of Philosophy, Pacific Lutheran University, and author of Strong Medicine: The Ethical Rationing of Health Care and Medical Costs, Moral Choices: A Philosophy of Health Care Economics for America.

${ }^{1}$ See Leslie Pickering Francis, Consumer Expectations and Access to Health Care, 140 U. PA. L. REV. 1881, 1892-97 (1992).

${ }^{2}$ See id. at 1892-93. 
dispute will then primarily focus on the alleged fact of encouragement. Our inclination against the defendant here is the strongest when we can think of the thing that is unreasonable as not only the expectations that were encouraged, but the encouragement itself.

Perhaps this can be used to clarify Professor Francis's treatment of Firestone Tire $\mathcal{E}$ Rubber Co. v. Burch, ${ }^{3}$ Adams v. Blue Cross/Blue Shield, ${ }^{4}$ and Brown v. Blue Cross $\mathcal{E}$ Blue Shield. ${ }^{5}$ Since the creation of inflated expectations is so inherent and significant a problem for any context of insurance, employers and insurers ought to clarify to employees and subscribers just what limitations to coverage are involved. If they do not, they will have unreasonably (though unwittingly, perhaps) encouraged unreasonable expectations. If they do clarify those limitations, however, they will have refused to encourage allegedly unreasonable expectations and the burden of proof will shift to the plaintiff to show that the defendant who ultimately denies coverage is disappointing a reasonable expectation nonetheless. Specifically, if all an insurance plan says is that it will pay for all care that is "medically necessary treatment" and leaves that undefined, the terrible ambiguity of "medically necessary" prevents us from holding plaintiffs responsible for curbing their expectations; de novo judicial review of the substance of the issue of whether the disputed item is necessary (reasonable?) care will be warranted. Or if Blue Cross and Blue Shield of Maryland utters virtual double-speak by defining uncovered "experimental or investigative" treatments as "any treatment ... not generally acknowledged as accepted medical practice by the suitable medical specialty practicing in Maryland, as decided by $u{ }^{\prime \prime}$, ${ }^{\prime 6}$ the defendant should be held to independent court review of what constitutes "experimental and investigative" measures. On the other hand, if coverage is explicitly and much more clearly limited to "medically necessary treatment as defined by the plan administrator," a denial of coverage should be reviewed under a standard more deferential to defendants.

All of this illustrates that the law can play a constructive role in helping a society get expectations under control while also paying serious attention to their conditional moral weight. Resolving the

${ }^{3} 489$ U.S. 101 (1989).

4757 F. Supp, 661 (D. Md. 1991).

${ }^{5} 898$ F.2d 1556 (11th Cir. 1990); see Francis, supra note 1, at 1907-10 (discussing these three cases).

${ }^{6}$ Adams, 757 F. Supp. at 663 (emphasis added) (quoting the Blue Cross Plan). 
many dilemmas that arise in walking this thin but necessary line, however, will not be easy. Take, for example, cases where financial interest may distort substantive judgment about "medical necessity" or "investigational therapy." Professor Francis reads the Eleventh Circuit Court of Appeals in Brown as "shifting the burden of proof to the fiduciary to show that its decision was not self-interested, when[ever] the fiduciary stands to profit financially from the benefits denial. $" 7$ On the one hand this makes sense: the fiduciary cannot be trusted to interpret the language of the agreement if she has a financial conflict of interest. On the other hand, virtually all reasonable limitations on care are still self-interested, feeding constructively into an insurer's or provider's profits. A legal test involving lack of self-interest once a possibility of profit looms on the horizon would seem to immobilize the society in coming up with arrangements that will effectively remove providers' incentive to overtreat.

This may be why Professor Francis acknowledges later that "[p]erhaps employers are right to insist that decisions to deny benefits should be given highly deferential review" as long as "they have drafted the plan to reserve discretion [explicitly] to the plan administrator. ${ }^{n}$ She means, I take it, that this is right under these conditions even when the possibility of financial self-interest is present. Professor Francis indicates her and our nervousness, though, by the "perhaps." About such a world in which the responsibility for deciding what care will be covered is simply contractually assigned to providers or insurers, she notes: "Then the moral question to ask is whether it would be desirable to create a world of such uncertainty. "9 The procedure has been made clear, but not one iota of the substance has.

What we yearn for is some sense of a substantive standard for what constitutes a reasonable level and scope of care. We want that precisely so that we remain able to form the reasonable expectations of care on which we can generally rely. The hardest work in getting health care law to line up roughly with our moral sense is for people-as individuals, groups, and society-to develop a substantive sense of what it is reasonable to expect in the way of coverage. The alignment here of expectations with reality could, I suppose, just have to wait and get hammered out in the sheer course of events

\footnotetext{
${ }^{7}$ Francis, supra note 1, at 1909.

8 Id. at 1914.

${ }^{9} I d$. at 1916.
} 
that actually unfold in our society, regardless of any sense of what level and scope of care a human person has any moral right to expect. ${ }^{10}$

Professor Francis has not gone far enough to develop such a sense, but she has seen a fundamental point of connection between the larger culture and health care law: consumer expectations, and expectations that it is reasonable to encourage. She is right to accord significant weight to contractual language, but also right to insist that there remain other important moral issues about expectations.

${ }^{10}$ I have tried elsewhere to defend the moral propriety of tailoring health care to the level and scope of care that actual, rational, and self-interested persons, before the time at which they know they are afflicted with the conditions that need treatment, would be willing to commit themselves to paying for with their accessible private and public resources. See Paul T. MEnZEL, STRONG MEdicine: THE ETHICAL RATIONING OF HEALTH CARE 15-29 (1990). This "prior consent" approach, which under certain conditions is justified in invoking presumable prior consent, is only a conceptual direction. It is not a formula from which we can crank out precise answers to questions about what expectations are reasonable. If its essential idea would take hold in the culture, however, it would engender in people a sense of responsibility for their expectations of the level of care that they thought they had a right to receive. 